\title{
Procesos territoriales y bosques en la cuenca del río Valdivia (siglos XVI-XIX) ${ }^{1}$
}

\author{
María Eugenia Solari² ${ }^{2}$ Clara Cueto ${ }^{3}$, Fernando Hernández ${ }^{4}$, \\ Juan Facundo Rojas ${ }^{5}$ y Pablo Camus ${ }^{6}$
}

\begin{abstract}
RESUMEN
La dinámica de los bosques en la cuenca hidrográfica del río Valdivia no posee una retracción linealmente creciente en relación al avance de la cultura europea colonizadora en la región, sino muestra diferentes pulsos acorde a los procesos adaptativos surgidos del contacto entre estos pueblos. En este marco se busca proporcionar respuestas sobre distribuciones y procesos territoriales, en función de diversas modalidades de apropiación del espacio, a partir de un enfoque interdisciplinario donde converge la historia ambiental, arqueología, antropología y geografía (incluidos los SIG). Principalmente, a partir del análisis de contenido sobre fuentes historiográficas y arqueológicas, en conjunto con trabajo cartográfico, se pretende profundizar y validar las explicaciones sobre la construcción histórica de los paisajes regionales, que fue mediada por obstáculos y oportunidades ambientales, por posibilidades tecnológicas y por dinámicas político-culturales de negociación y dominación, que lejos estuvieron de significar procesos lineales, homogéneos y estáticos de transformación de la cuenca de Valdivia.
\end{abstract}

Palabras clave: Bosque valdiviano, historia ambiental, cuenca hidrográfica río Valdivia, procesos territoriales, Sistemas de Información Geográfica.

\begin{abstract}
Receding of the native forest in the Valdivia river catchment was not directly related to the advancement of the European settlers in this region. It responded, however, to pulses from adaptive processes that originated from the interactions between the native communities and the European settlers. Based on this framework and a interdisciplinary approach where environmental history, archaeology, anthropology, geography and Geographic Information Systems meet, we aim to find answers regarding the distribution and territorial processes linked to the different patterns of land appropriation in the area. By studying historiographic and archaeological resources, along with cartographic studies, we expect to validate and thoroughly understand the explanations about the historical transformation of this regional landscape. A transformation that was shaped by environmental obstacles and opportunities, technological capabilities and political and cultural dynamics of trade and dominion, all of them far from being lineal, homogenous and static processes.
\end{abstract}

Key words: Valdivian forest, environmental history, Valdivia river catchment, territorial processes, Geographic Information Systems.

1 Esta investigación se ha desarrollado en los proyectos FONDECYT No 1040326 y 1090465 : "Los paisajes del agua: prácticas sociales y sustentabilidad en la cuenca hidrográfica del río Valdivia". Artículo recibido el 24 de marzo de 2010, aceptado el 24 de mayo de 2010 y corregido el 20 de julio de 2010.

2 Laboratorio de Arqueobotánica e Historia Ambiental, Universidad Austral de Chile (Chile). E-mail: msolari@uach.cl
3 Facultad de Filosofía y Letras, Universidad Nacional de Cuyo (Argentina). E-mail: claracueto@yahoo.com.ar

4 Facultad de Filosofía y Letras, Universidad Nacional de Cuyo (Argentina). E-mail: josefernah@gmail.com

5 Instituto Argentino de Nivología, Glaciología y Ciencias Ambientales, CONICET (Argentina). E-mail: frojas@mendoza-conicet.gob.ar

6 Instituto de Historia, Pontificia Universidad Católica de Chile (Chile). E-mail: pcamusg@uc.cl 
Si bien en la cuenca hidrográfica del río Valdivia predominó el bosque como componente fundamental del ambiente desde el Holoceno medio hasta mediados del siglo XIX, esta interacción muestra espacios cautivos por poblaciones diversas que intervinieron el ambiente natural para habitarlos y establecer de este modo diferentes prácticas culturales asociadas a la caza y recolección y a la agroganadería. Desde fines del siglo XVI fue perceptible el aumento progresivo de los bosques en relación con las tierras despejadas dispuestas para la agricultura u otras actividades humanas al momento del contacto indígena-español, especialmente desde el río Toltén hacia el sur. La lectura de crónicas y relatos de la época demuestra la existencia de menos bosque y más zonas despejadas y pobladas que en el siglo XIX, teniendo parte de la exuberante vegetación encontrada por los viajeros y exploradores del siglo XIX poco más de dos siglos de existencia. El descenso demográfico provocado por la conquista y colonización, sumado a un cambio en la estrategia adaptativa, tanto de las comunidades originarias como colonizadoras, habría permitido el avance de los bosques en la región durante los siglos XVII y XVIII (Camus y Solari, 2008).

Uno de los objetivos propuestos es identificar los patrones y tipos de distribución en la apropiación, movimiento y aprovechamiento de los recursos en la cuenca valdiviana. En relación a ello, se propone la hipótesis de que dichos procesos han sido diferenciales en el territorio, no solo de acuerdo al grupo social que se analice, sino que la dinámica de los mismos grupos en distintos períodos es cambiante, de acuerdo a diferentes procesos adaptativos y mutaciones político-culturales que emergen. En ese sentido, a partir del anterior trabajo de Camus y Solari (2008) sobre esta temática, se profundizó con el aporte de nuevas fuentes, la revisión de las anteriores y la confección de cartas georreferenciadas.

Este documento se sustenta en la propuesta que considera a la historia ambiental como el estudio de las interacciones e influencias recíprocas, entre las sociedades y sus medio ambientes a lo largo del tiempo (Jori, 2009; Worster, 1989). En este sentido, se trabaja en un contexto interdisciplinar y de reciprocidad entre saberes científicos propios de las ciencias naturales (cambios geográficos, geológicos, climáticos, vegetacionales, faunísticos, entre otros) y los mecanismos adaptativos de las sociedades (Pounds, 2000). La relectura de documentos históricos en clave ambiental, se constituye en una de las fuentes principales para estos estudios, en los cuales se rastrean informaciones que puedan aportar a las reconstrucciones de la relación entre sociedad y medio ambiente natural.

Desde esta perspectiva se pretende reconstruir procesos, más que describir y explicar acciones y acontecimientos humanos del pasado (Sieferle, 2001). Para Worster (1989), la finalidad principal de este campo de investigación es comprender cómo los seres humanos han sido afectados por la naturaleza y cómo, a su vez, estos han impactado el ambiente natural y con qué resultados.

Además del análisis documental, se estudian diferentes elementos del paisaje actual que evidencien las modalidades de inserción y aprovechamiento del entorno natural de los pueblos originarios, de los colonos españoles y eurochilenos. En este punto adquiere gran importancia la geografía con su bagaje teórico que proporciona diferentes medios para interpretar los paisajes y explicar este tipo de influencias socioambientales (Jori, 2009).

Para lograr repensar esta relación se trabaja con un enfoque interdisciplinario donde convergen aportes de la historia ambiental, la arqueología, la antropología y la geografía. Esta última ciencia se presenta como un eje integrador, de marcos explicativos de otras disciplinas plasmados sobre el territorio, en los cuales se manifiesta la interacción entre procesos sociales y ambientales, que la geografía supo estudiar desde sus comienzos.

Se incorporan también Sistemas de Información Geográfica (SIG) para la representación cartográfica de los aspectos esenciales de la relación entre sociedad y ambiente para los diferentes períodos temporales. La incorporación de estas modernas herramientas resulta de gran valor instrumental y teórico, puesto que permiten al mismo tiempo la localización precisa de fenómenos y el trabajo 
con grandes cantidades de datos georreferenciados, ofrece también la posibilidad de profundizar el análisis y reflexión de los procesos estudiados postulando nuevas hipótesis y ampliando las explicaciones (Wheatley \& Gillings, 2002).

\section{Descripción del área de estudio}

El estudio se desarrolla en la cuenca binacional del río Valdivia que se ubica entre los $39^{\circ} 19^{\prime}$ y los $40^{\circ} 03^{\prime}$ de latitud sur y los $73^{\circ} 28^{\prime}$ y los $71^{\circ} 42^{\prime}$ de longitud oeste. Abarca una superficie de $11.110 \mathrm{~km}^{2}$. Su fuente es el lago Lacar, en la provincia de Neuquén (Argentina) y le pertenecen las comunas chilenas de Loncoche y Villarrica en la IX Región y San José de la Mariquina, Lanco, Panguipulli, Máfil, Valdivia, Los Lagos, Corral, Paillaco y parte de Futrono, en la XIV Región de los Ríos.

La región de Valdivia es una cuenca interior de carácter tectónica, que se conforma como un plano depositacional extenso, relativamente bajo y afectado por una tectónica de hundimiento que ha sido cubierto por depósitos volcánicos en ambientes marinos, lacustres, fluvioglaciales, glaciales y aluviales, estos últimos correspondientes al período posglacial, donde han sido sometidos a procesos de hundimiento constante. En esta región se encuentra el río Valdivia cuya cuenca presenta una gran variabilidad altitudinal comenzando desde el nivel del mar hasta alcanzar los 2.847 m y 2.422 m, correspondientes a los volcanes Villarrica y Mocho-Choshuenco, respectivamente; y los $720 \mathrm{~m}$ en el cerro Oncol en la cordillera de la Costa (Farías, 2006), hallándose dominada por el estrato altitudinal que va entre los 200 m y $250 \mathrm{~m}$. En función de esta variabilidad altitudinal se reconocen tres sectores (Subiabre y Rojas, 1994):

1. En el oriente se inicia en la cordillera de los Andes, en cuyo piedemonte se insertan una serie de lagos de origen glacial afectados directamente por procesos de volcanismo desde su formación.

2. El sector medio de la cuenca se ha denominado depresión occidental y se extiende desde los Ciruelos por el este y
Puringue por el noroeste, hasta el sureste y suroeste por un descenso en altura que alcanza $38 \mathrm{~m}$ en el río San José y 8 m en la plaza de la ciudad de Valdivia, limitando definitivamente en la ribera norte del río Angachilla.

3. La zona costera presenta características propias que la diferencian de la cordillera de los Andes y comprende dos unidades geomorfológicas relacionadas, la cordillera de la Costa propiamente tal, compuesta por una serranía caracterizada por lomas suaves y mesetas propias de toda la región centro sur y la franja continua de la costa que presenta bahías consideradas como rías, interrumpidas por roqueríos de difícil acceso, terrazas de Cancahua a la altura de Valdivia y vegas hacia el sur, las que quedaron bajo el nivel del mar luego del terremoto de 1960. En la cuenca de Valdivia el relieve costero se ve interrumpido por el valle del río homónimo.

La cuenca de Valdivia se ubica en la zona denominada oceánica o Iluviosa (Castri y Di Hajek, 1976). En esta zona los doce meses del año son húmedos, en promedio precipitan $3.000 \mathrm{~mm}$ anuales, aunque en época estival las precipitaciones disminuyen, no deja de ser una estación con humedad suficiente para la demanda evapotranspirativa. Estas condiciones climáticas de temperatura y humedad tienen influencia directa en las características de la vegetación, generando el denominado Bosque Valdiviano. Las abundantes precipitaciones originan comunidades boscosas de cobertura muy densa siempreverdes y en múltiples estratos, con ejemplares de gran tamaño, una alta biodiversidad y endemismos. Las temperaturas actúan, en época invernal, como limitantes al crecimiento arbóreo (Armesto et al., 1996). En ámbitos académicos existe una discusión sobre los límites del bosque valdiviano que recopilan Luebert y Pliscoff (2005).

Las dos formaciones forestales dominantes en la cuenca valdiviana corresponden a bosques secundarios, principalmente de Roble (Nothofagus obliqua), Raulí (Nothofagus alpina), Coigüe (Nothofagus dombeyi) y Tepa (Laureliopsis philippiana). Otras especies con amplia distribución son Ciprés de las Guaitecas (Pilgerodendron uviferum) y Ciprés de la Cordillera (Austrocedrus chilensis). 
Hay que destacar la importancia de los bosques de Araucaria (Araucaria araucana) ubicados al noreste de la región y Alerce (Fitzroya cupressoides) al suroeste (Donoso, 2005). Ambas son especies emblemáticas que comparten biografías culturales paralelas, que transitan desde los imaginarios de las poblaciones de cazadores recolectores holocénicas, las poblaciones agroganaderas mapuchehuilliches, hasta su mercantilización histórica y su reciente patrimonialización jurídica. De esta manera los bosques evidencian prácticas sociales diversas y cambiantes que, desde el período de contacto, significaron una mayor presión antrópica multicultural especialmente sobre las poblaciones de Araucaria, ubicadas en los múltiples pasos cordilleranos de la Araucanía y, por la explotación maderera del Alerce, efectuadas en la cordillera de la Costa de la ecorregión valdiviana (Solari et al., 2007). Desde una perspectiva ecológica “... (estos) bosques costeros de Chile podrían ser severamente afectados por la extracción masiva de biomasa y las pérdidas de suelo orgánico..." (Arroyo et al., 1998: 49), que implicaría además una importante degradación a nivel ambiental de la biodiversidad de estas comunidades boscosas de enorme valor a escala regional.

Las características climáticas en la región sumada a la acción erosiva de los glaciares tienen una gran influencia en las características hidrográficas de la cuenca. En este sentido, se localizan una gran cantidad de ríos y lagos. Los ríos poseen poca pendiente y son regulados en su caudal por los diversos lagos que se encuentran en ella, esto favorece su navegabilidad. Los sistemas hidrográficos más importantes de esta región son los ríos Valdivia, Bueno, San Pedro y Callecalle. Además se destacan lagos como el Calafquén, Panguipulli y Riñihue (Educarchile, 2010).

Las sociedades que han habitado a lo largo de la historia en esta cuenca han sido testigos de eventos geológicos y climáticos extremos como erupciones, sismos, tsunamis, aluviones, inundaciones y sequías, cuyo impacto en la sociedad local deja huellas que las generaciones conservan en su memoria y encarnan en sus prácticas (Aceituno et al., 2009).

\section{Metodología de trabajo}

Para responder a los objetivos anteriores se utilizó una metodología tradicional de la historia ambiental desarrollada previamente por Abraham \& Prieto (1991), que consiste básicamente en la comparación de la situación histórica del ambiente, determinada a partir de una línea base (en este estudio representada por el momento de contacto indígena-español) con la existente en distintos períodos históricos posteriores. Esto se realiza mediante tres etapas, en primer lugar la caracterización de los fenómenos a estudiar, posteriormente el rescate textual y por último el análisis de contenido.

\section{Caracterización de los fenómenos a estudiar}

Las categorías de análisis establecidas se pueden agrupar de la siguiente manera: asentamientos, incluye de indígenas (territorios lof contemporáneos en tierras reconocidas como indígenas y sitios arqueológicos), de españoles (ciudades, villas, fuertes y misiones religiosas), y de colonos eurochilenos (siglo XIX). Territorios de conflictos y alianzas, actividades económicas, relacionadas con cultivos, minas de oro, astilleros, aserraderos y rutas comerciales. $Y$ presencia de bosquestierras despejadas o desforestadas, desastres naturales (inundaciones y vulcanismo).

\section{Rescate textual de la información}

Se utilizaron como fuentes de información trabajos de distintos autores sobre la historia local, relatos de cronistas, viajeros, misioneros, naturalistas, cartografía histórica, cartas a ministros, relaciones, oficios y memorias, de las cuales se extrajeron citas referidas a las categorías de análisis previamente establecidas en función de los objetivos ${ }^{7}$. En este sentido, es fundamental, en esta parte del trabajo, que las citas extraídas posean localización espacial precisa. En esta investigación, existe la limitante de algunas citas que no reúnen

\footnotetext{
Para lo cual se construyó una base de datos, estructurada en filas y columnas, aludiendo a: categoría de análisis, momento histórico, localización, cita propiamente dicha y su fuente bibliográfica.
} 
esta condición. Por otra parte, se utilizaron fuentes secundarias de información como territorios lof (Araya et al., 2003) y sitios arqueológicos (Solari et al., 2007), estos datos georreferenciados permitieron enriquecer la categoría de análisis relacionada con los asentamientos de pueblos originarios.

Al mismo tiempo se utilizó cartografía base de distintas fuentes referente a lagos, topografía, imágenes satelitales, ríos, regiones y provincias chilenas, ciudades y localidades actuales provenientes del Instituto Geográfico Militar de Chile.

La cantidad total de citas históricas trabajadas y revisadas fue de 540, aunque es necesario aclarar que muchas no tuvieron un peso importante en los resultados del trabajo por su falta de precisión espacial o ambiental. De este total correspondieron 132 al período de poblamiento y fundación de enclaves españoles (1552-1599), 53 al período de recuperación territorial indígena (1599-1644), 197 al de repoblamiento español y dependencia virreinal (1645-1810), por último, 158 al período de independencia y colonización eurochilena (1810-1890) ${ }^{8}$. Se debe señalar que en varios casos una cita hace alusión a más de una categoría de análisis.

\section{Análisis de contenido de las fuentes}

Se procedió a la comprensión crítica de las fuentes históricas, antecedentes y contribuciones diversas, apuntando a realizar un análisis de contenido, de discurso y semántico para generar categorías de análisis a partir del texto y diferentes equivalencias de significado. Se parte de la base de que los seres humanos comunican sus impresiones sobre su entorno de acuerdo con los códigos de su propio tiempo histórico y que estos son normalmente diferentes a los del presente. Es necesario entonces descubrir las formas lingüísticas inherentes a cada época, para reducir a un lenguaje común, comprensible en la actualidad, las diversas formas de expresión adoptadas a través del tiempo (Prieto, 2000).

8 Estos períodos surgen a partir de la lectura de Guarda (2001).
Otras consideraciones importantes en este tipo de análisis son:

- Determinar categorías de análisis.

- Distinguir quién fue el observador del evento y su autoridad para calificarlo. Puede tratarse de una observación personal, un informe de segunda mano, un rumor, una invención, entre otros.

- Verificar si el informe es creíble totalmente, en forma parcial o no lo es en absoluto.

- Verificar las modificaciones en el vocabulario para referirse a fenómenos naturales, según la época y el emisor del texto.

En algunos casos esta metodología permite determinar indicadores y calificar los eventos de acuerdo a su magnitud, estableciendo un rango entre fenómenos de la misma naturaleza.

Este trabajo se complementó con el aporte de herramientas SIG (Sistemas de Información Geográfica). Los SIG representan un importante aporte a la comprensión de la historia cuando se utilizan adecuadamente, de manera que los niveles de precisión y particularidades de los datos históricos queden fielmente reflejados en los sistemas cartográficos (Ian \& Ell, 2007).

Son variadas las respuestas que pueden ofrecer los SIG a este tipo de estudios de historia ambiental, algunas de las más relevantes son los análisis de tendencias y cambios temporales en el territorio, la elaboración de modelos predictivos o la reconstrucción de paleoambientes. Su uso ha sido muy bien ponderado por diferentes disciplinas, en el caso de la historia, para examinar exhaustivamente cómo el espacio se puede incorporar a la disciplina (Ian \& Ell, 2007), repensándola ya no tan solo desde la cronología de los eventos.

Mediante el uso de los SIG se realizaron cartas georreferenciadas ${ }^{9}$ que reflejan parte de los procesos históricos que son producto de las relaciones entre diferentes sociedades

9 Se utilizó proyección UTM, Huso 18 y 19 hemisferio sur, con Datum 69 Sudamericano. La cartografía base se obtuvo del Instituto Geográfico Militar (IGM) Chile, de World Wild Fundation (WWF) y de un modelo digital realizado por Aldo Farías (WWFValdivia). 
y sus ambientes naturales. Estos procesos dieron forma a la configuración actual del área de estudio.

Los objetivos que guiaron el trabajo apuntaron a encontrar evidencias, a partir de la cartografía y el análisis de documentos históricos y sitios arqueológicos, que permitieran explicar los avances y retrocesos del bosque situado en la ecorregión valdiviana, las lógicas del poblamiento y de los itinerarios por el territorio de los diferentes grupos, tanto autóctonos como alóctonos, a partir de procesos históricos vinculados a los períodos de conquista, de recuperación indígena y de consolidación de la república. De esta manera la sociedad indígena fue sustituida paulatinamente -a pesar de los ritmos marcados anteriormente- por una sociedad eurochilena que ocupa espacios de la cuenca, vinculando estos territorios con otros enclaves colonizadores.

\section{Resultados}

Los procesos ambientales más aludidos por las fuentes en el período de poblamiento y fundación de enclaves españoles (15521598), corresponden a descripciones bastante generales del ambiente con miradas que lo interpretan exclusivamente como fuente de recursos a explotar. Aun así los relatos muestran gran dinamismo productivo, comercial y poblacional. Para dichos momentos se recopilaron 132 citas de las fuentes, pero solo algunas decenas concentraron la más rica información ambiental. Los autores más relevantes al respecto son: Vicente Carvallo y Goyeneche, Alonso de Góngora Marmolejo (1862), Pedro Mariño de Lovera y Gerónimo de Vivar (1979). En general, las crónicas de la época poseen información ambiental escasa e incierta, con énfasis significativos en algunos temas y sectores y ausencia en otros. Concretamente, los procesos ambientales que adquieren más notoriedad están relacionados con el aumento de las precipitaciones en el territorio valdiviano en relación a regiones más septentrionales, referidos a la existencia de zonas montuosas (bosques) muy útiles para la explotación ${ }^{10}$.

\footnotetext{
${ }^{10}$ Cabe destacar que, de acuerdo con la información documental, la presencia de bosque en muchos sec-
}

La conquista europea del territorio se impuso en los primeros cincuenta años sobre un pueblo originario que contaba con una importante población ocupada principalmente en la agricultura, documentada por los sitios arqueológicos y por las primeras descripciones de la comarca de Valdivia, efectuadas por los españoles.

La distribución de sitios arqueológicos muestran que los pueblos originarios están asentados en torno a los lagos, los ríos, con una distribución predominante oeste - este, valorizando, desde el holoceno temprano los diferentes ambientes de la cuenca (Solari et al., 2007; Bengoa, 2003). Por lo anterior, es necesario aclarar que, a pesar de no estar representadas en el mapa por una cuestión de escala, en torno a la mayoría de los sitios arqueológicos correspondientes al período agroalfarero, se localizaban áreas con cultivos. Según Mariño de Lovera (1861): “...en Valdivia había un asentamiento donde tenían sus viviendas los naturales en razonables casas. Entraron los nuestros por esta loma y viéronla toda tan adornada de arboleda, sembrada a mano, que parecía un paraíso" (Mariño de Lovera, 1861: 136).

El territorio que circunda San José de la Mariquina era uno de los más productivos y habitados, como relata Mariño de Lovera (1861) al encontrar "...unas grandes llanadas, tan llenas de poblaciones, cuanto abundantes sementeras de maíz, fréjoles, papas, quínoa, y otros granos y legumbres" (Mariño de Lovera, 1861: 39).

Las formas de ocupación y aprovechamiento territorial hispanas e indígenas hacen suponer un nivel de impacto, aunque diferenciado sobre el bosque, de relativa importancia durante el siglo XVI "...En esta comarca existían más de 500 mil indios en 10 leguas, y está muy abastecido de maíz, legumbres y frutas de la tierra... la tierra es algo montuosa pero de grandes recreaciones; porque tiene cipreses pequeños, y otros muchos árboles deleitables; ....sácase de ella mucha madera

tores del territorio es supuesta por defecto, debido a la ausencia de cultivos documentados y a las condiciones geográficas, altitudinales y ambientales de los diferentes sectores. 
estremada para edificios, y gran fuerza de tablas anchas como de cedro, de que van al Perú navíos cargados" (Mariño de Lovera, 1861: 136).

Haciendo referencia a los asentamientos españoles en la cuenca, a la extensión de sus cultivos/tierras desforestadas y áreas ocupadas por el bosque nativo, se puede observar que en la depresión intermedia se encontraban las mayores extensiones de cultivos. Pedro González de Agüero (1791) plantea que: "...los terrenos de Valdivia aseguran los historiadores que son abundantes de trigo, legumbres y frutas... las islas que se hallan en las inmediaciones son capaces de cultivo y de mantener ganado, por sus muchos y útiles pastos y podría ser todo aquel país fecundo y delicioso las proporciones que por sí ofrecen sus terrenos" (1791: 33). A su vez, Diego Ro- sales (1877) señala que en los llanos “...los vecinos de la ciudad tenían copiosísimas sementeras de trigo, cebada, garbanzos, lentejas y otras legumbres" (Rosales, 1877: 408).

También se resalta la presencia de cultivos en torno a los emplazamientos de Valdivia, Arique, Quinchilca, San José de la Mariquina, los Llanos de Osorno y Unión, Panguipulli, Guanehue y Calafquén, en ocasiones diferenciándose entre cultivos españoles e indígenas (Figura $\left.\mathrm{N}^{0} 1\right)^{11}$.

\footnotetext{
${ }^{11}$ En las fuentes trabajadas se observó una fuerte correlación, para la descripción de bosques y zonas cultivadas, con la cartografía histórica realizada por Donoso (1983). Por ello, esta cartografía fue incorporada a las nuevas fuentes trabajadas.
}

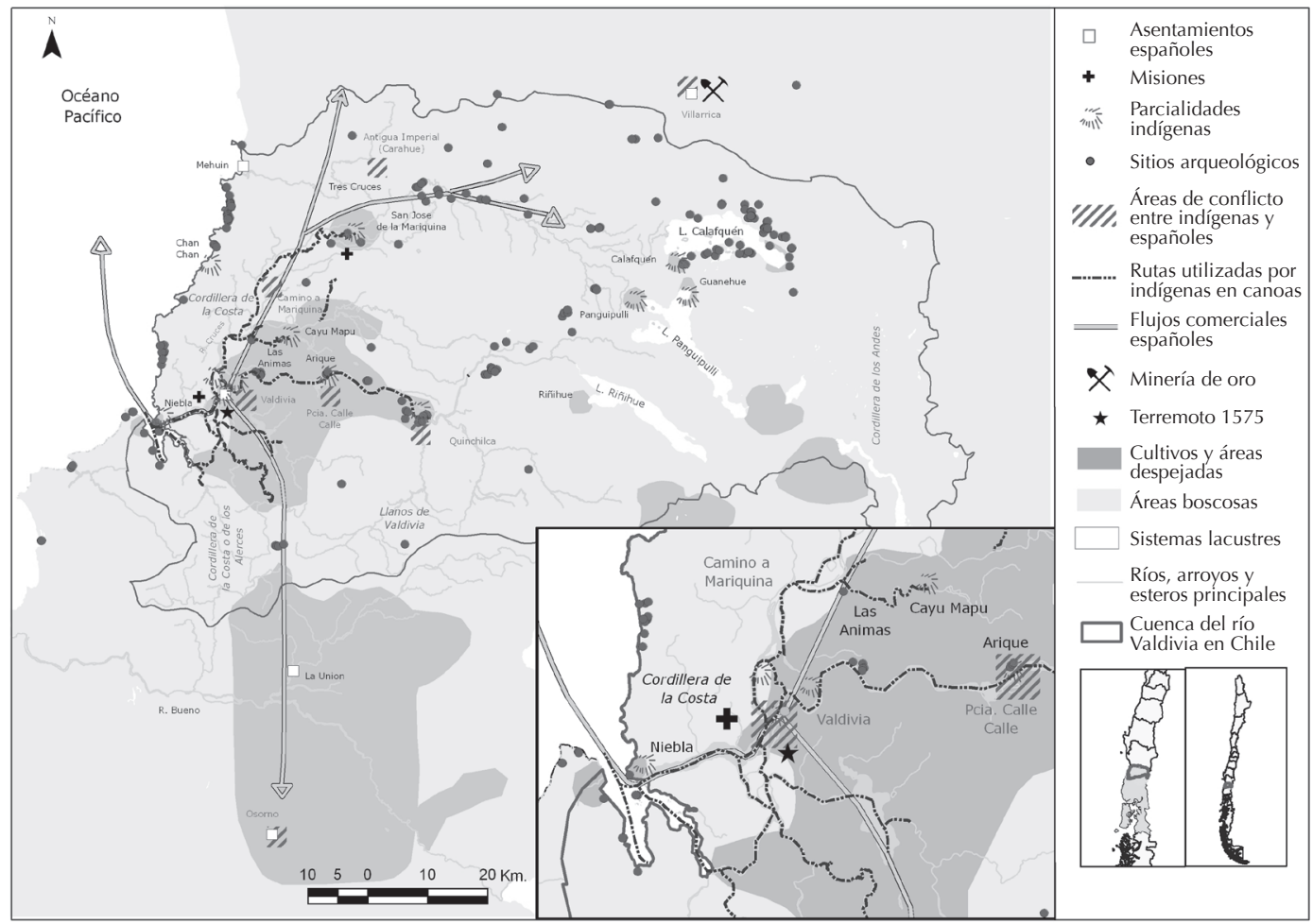

Fuente: Elaboración propia. 
Se marcó de este modo una zona intermedia, donde predominaban las áreas de conflictos y contacto que marcaban la frontera entre culturas en la segunda mitad del siglo XVI. Estas áreas reflejaban los límites del territorio que fueron los que más fuertemente sufrieron el impacto del conflicto indígenaespañol, hacia fines del siglo XVI. Carvallo Goyeneche (1876) relata que "después que Lautaro volvió a Arauco... deliberaron lanzar de aquel reino a todos los españoles i determinaron empezar por las ciudades de Imperial y Valdivia... Lautaro con diez mil indios para que atacase la ciudad de Valdivia..." (Carvallo Goyeneche, 1876: 90).

El proceso de reconquista indígena del territorio centro-sur de Chile produce cambios en sus propias estrategias adaptativas, al adquirir la ganadería euromediterránea como sustento. De este modo, una de sus estrate- gias principales, fue su repliegue hacia las áreas más orientales, lo que habría colaborado en el avance de los bosques en la depresión intermedia y valles costeros de la región durante los siglos XVII y XVIII (Camus y Solari, 2008). A partir de ese momento, principalmente en el sector oriental de la cuenca, se perpetúa como un espacio habitado por comunidades originarias que presentan un patrón mixto de producción agroganadero, en un paisaje de mosaico, producido por la tala y roce de superficies no extensivas, aledañas a las zonas lacustres y fluviales.

En el período de recuperación territorial indígena (1599-1644), representado en la Figura $\mathrm{N}^{\circ} 2$, se puede observar que los conflictos y levantamientos del primer período dan como resultado una expulsión paulatina del español, con la consecuente dominación indígena durante 45 años aproximadamente.

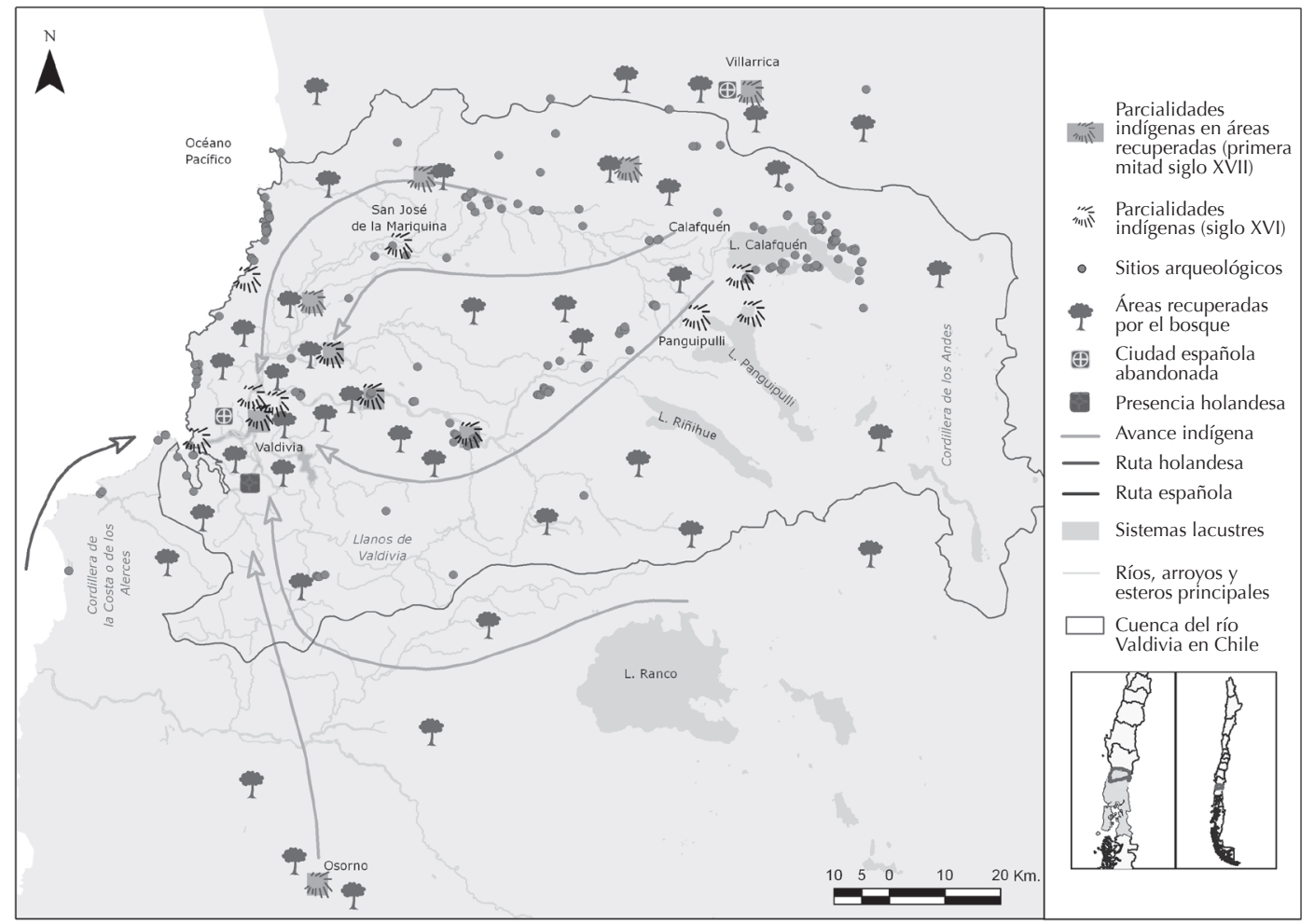

Fuente: Elaboración propia. 
Se utilizaron 53 citas entre las que destacan las de Carvallo Goyeneche (1861), Feliú Cruz, Juan de Aguirre (2000), entre otros. Solo alrededor de diez citas fueron las más significativas, pues el resto se refieren principalmente a cuestiones políticas sobre las guerras entre mapuches y españoles y su relación con los holandeses, refiriendo solo marginalmente temáticas relacionadas con el ambiente, el bosque y el comercio de recursos naturales.

El análisis de este período confirma lo establecido por Pounds (2000), se trata de un período de estancamiento, donde hay poca disponibilidad de fuentes documentales, lo cual se ve reflejado en el uso de información de siglos posteriores o del momento mismo del conflicto indígena-español.

Para este período los enclaves españoles, totalmente destruidos, se presentan como áreas recuperadas y de dominio indígena “...pues de 13 ciudades que había en este reino destruyeron los indios desde el año de 1599 las siete más ricas que son Valdivia, la Imperial, Angol, Villarrica, Santa Cruz, Osorno y Chillán" (De Aguirre, 2000: 34). Carvallo Goyeneche (1876) hace referencia a la destrucción de cultivos por parte de los españoles: "esto molestó a los caciques de la zona y se levantaron en armas en contra de los españoles, ...destruyendo todas las sementeras de que podían aprovecharse los españoles i tuvieron la arrogancia de atacar la ciudad con un cuerpo de seis mil hombres" (Carvallo Goyeneche, 1876: 68).

Al momento del conflicto, el análisis de los documentos históricos refleja claramente distintos frentes de indígenas que avanzaban desde el interior hacia la costa, como desde las regiones más septentrionales hacia el sur, expulsando al español del territorio. Esta estrategia se centró en la recuperación de la ciudad, como núcleo principal de dominio y puerta de entrada a toda la región de Valdivia.

Desde fines del siglo XVI e inicios del XVII, con la recuperación del territorio por la población mapuche sensu lato, fue perceptible el aumento progresivo de los bosques en relación con las tierras despejadas dispuestas para agricultura en el período anterior. Este proceso se produjo en especial desde el río
Toltén hacia el sur, dominio del bosque valdiviano siempreverde $y$, por tanto, en torno al área de influencia de las ciudades españolas de Valdivia y Villarrica. Todavía durante mediados de siglo XIX, Treutler (1958) reconocía en Villarrica que "un denso bosque cubría el lugar de la antigua ciudad y sus fortificaciones, restos de construcciones en pie le permitirían reconocer las calles y plazas, y los grandes edificios, como iglesias y monasterios" (Treutler, 1958: 373).

Ya en el siglo XVII sobre la ciudad de Valdivia se decía: “...son muchas las que de árboles y ramas han crecido a espesura de bosques, en aquel antiguo sitio que parece más que montaña áspera que humana habitación, que de la antigua han quedado muchas ruinas y paredes viejas de edificios caídos por tristes monumentos de los antiguos, y ricos solares..." (De Aguirre, 2000: 79).

Este proceso se representa en la cartografía a partir de íconos que señalan áreas recuperadas por el bosque. Particularmente los casos de Valdivia y Villarrica se destacan por la frecuencia de menciones en las fuentes.

La situación de debilidad española fue aprovechada por conquistadores holandeses que realizaron incursiones en la cuenca con el objetivo de instalar nuevos núcleos de dominio. Si bien no avanzaron en profundidad en la cuenca, sí lograron establecerse en Valdivia por un lapso breve. En este sentido, el espacio marítimo y fluvial cobra un interés particular ya que la presencia española y holandesa se manifiesta aquí especialmente, con sus movimientos de avance y retroceso.

"...Siendo incuestionable que los indios habían cobrado general odio a los españoles, y sentía gran inclinación y no menos confianza hacia el holandés, como se manifestaba en el hecho de que 470 chilenos se habían voluntariamente embarcado con sus mujeres e hijos a bordo de sus naves para ser transportados de Chiloé a Valdivia, donde tanto ellos como los holandeses habían recibido la mejor acogida de los caciques de Valdivia, Osorno, Cunco y Villarrica..." (Feliú Cruz, 1926: 118).

El sector de ingreso a la cuenca de Valdivia fue un espacio de conflicto y tensión per- 
manente entre los tres grupos. Los indígenas mantenían ciertas negociaciones con el holandés, intercambios de recursos y permisos de avance en el territorio, sin embargo, esta presencia no significó grandes extracciones de recursos forestales como en el período precedente.

La Figura $\mathrm{N}^{\circ} 3$ sintetiza el período que comprende el repoblamiento español y la dependencia virreinal (1645-1810), momento en que paulatinamente aumenta el nivel de información en documentos. El territorio de la cuenca va estableciéndose como un espacio de contacto, reflejado en la expansión de la jurisdicción de Valdivia (1750-1820), el sometimiento de los Huilliche y la incorporación de territorios indígenas independientes (oriente de Valdivia y sur del río Bueno), instaurándose un nuevo orden en las relacio- nes interétnicas, junto con la incorporación política del territorio a la corona y el asentamiento y expansión de misiones franciscanas (Solari et al., 2009).

Las fuentes de mayor utilidad para este período coinciden con el período anterior a las cuales habría que agregar Usauro Martínez (1898), De Ocaña (1987), De Ovalle (1888). A su vez autores posteriores se refieren a este periodo: Pérez Rosales (1852; 1859), Guarda, Domeyko (1850). Se extrajeron 197 citas históricas de estas fuentes aunque el número efectivamente útil rondó las 40 citas.

Este período supuso la incorporación de economías más extractivas que las del período anterior. Sin embargo, posiblemente por razones políticas y tecnológicas principal-

Figura $N^{\circ} 3$

Ocupación y ambiente en el período de repoblamiento español y dependencia virreinal (1645-1810)

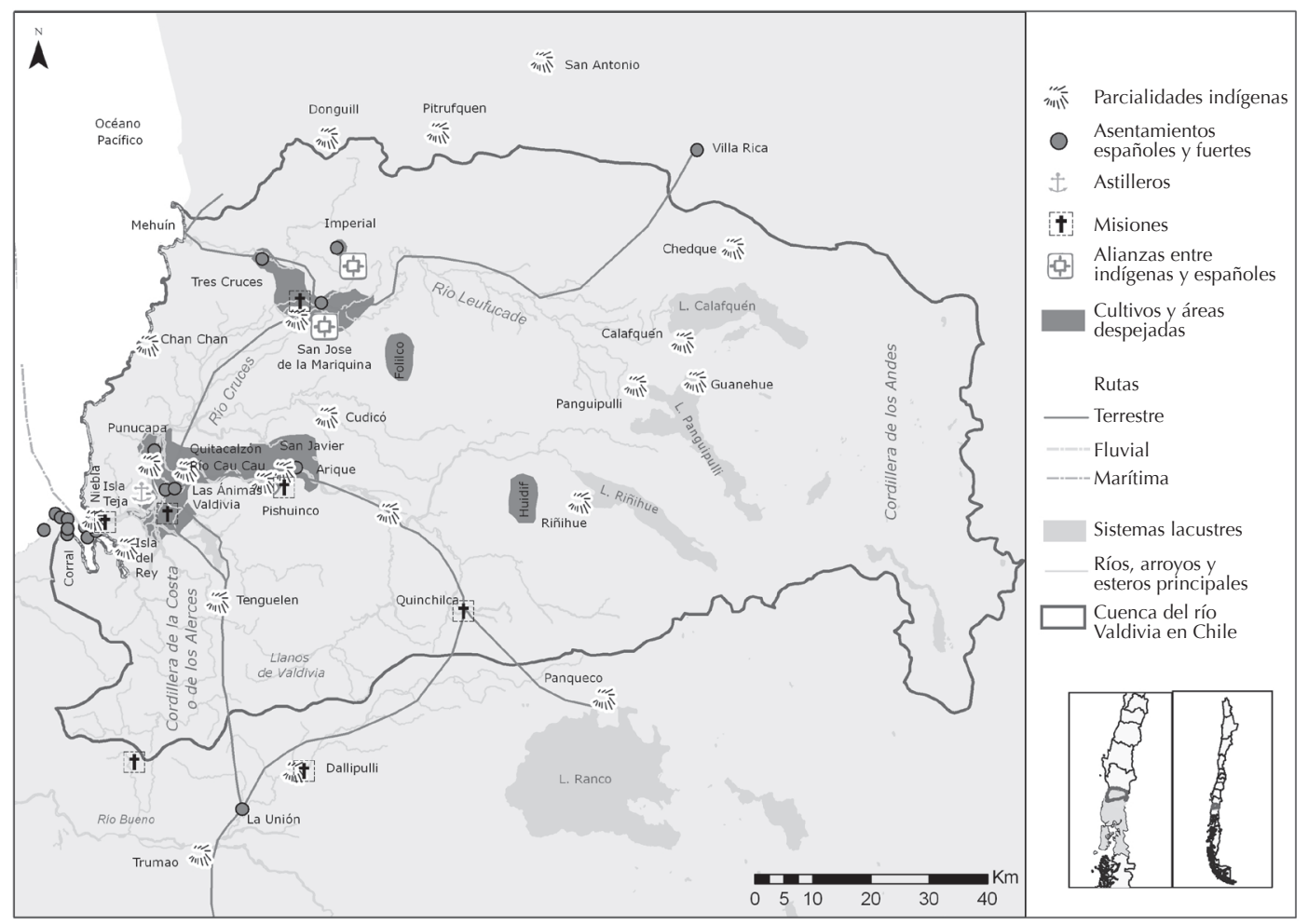

Fuente: Elaboración propia. 
mente, no continuó el ritmo y la intensidad del avance sobre los pueblos originarios y sobre su ambiente oriental, como había sucedido en los primeros 50 años de conquista. Esto significó que las modalidades de uso productivo del bosque se intensificaron principalmente en torno a Valdivia, San José de la Mariquina y Arique, como sucedió anteriormente durante el siglo XVI, mientras que las áreas boscosas orientales se mantuvieran más o menos estables hasta el período de colonización alemana que se inicia a mediados del siglo XIX.

En palabras de Usauro Martínez (1898), "lo montuoso del terreno es fomentado por la mucha humedad, que engruesa los árboles con prontitud y cubre de bosque las rozas..." (Usauro Martínez, 1898: 80); esta explicación del siglo XVIII muestra la rapidez de la reforestación natural que debe haber cumplido un papel nada despreciable en estas dinámicas ambientales.

Un enfrentamiento armado ocurrido durante enero de 1759 entre los indios Juncos y Huilliche, en el fuerte de San Fernando a orillas del río Bueno, bien sirve para mostrar la situación del denso bosque "...considerando que el tramo de tierra que hayar de Valdivia a Río Bueno, sobre ser dilatado, en partes... [frondoso] y cubierto de montes, y por estar expuesta cualquier retirada por sus avenidas; se abrió primeramente a punta de hacha en un bosque de más de 6 leguas de espesor camino capaz de admitir 6 hombres de frente y en la parte contrapuesta donde termina en un sitio nombrado Huenquecura se levantó un fortín competentemente guarnecido de armas..." (ANCH, 1759: 790). A su vez, CarvaIlo Goyeneche (1876) remarca la particularidad de esta zona: "la ciudad de Valdivia entre ella i Río Bueno son montañas inaccesibles i tierras incógnitas para los españoles..." (Carvallo Goyeneche, 1876: 188).

En este período, respecto del primero, se observa una mayor presencia de enclaves españoles en la región occidental, lo que permite la accesibilidad a otros centros colonizadores, situados en el eje norte-sur, por vía marítima y fluvial. A diferencia de los períodos precedentes se incorporan mayor cantidad de fuertes y misiones. Esta situación revela la necesidad militar e ideológica de los españoles de consolidar el dominio territorial. Otras estrategias utilizadas para el mismo fin eran las alianzas. En la región oriental de la cuenca se observa ausencia de misiones y fuertes, y un aumento de parcialidades en relación a lo manifestado durante el siglo XVI. La causa de esta situación se puede explicar como resultado de un proceso de avance de los españoles y el consiguiente replegamiento de los grupos indígenas hacia el este. Esta expulsión de los Ilanos (la depresión intermedia) obligó al indígena, desde el siglo XVII, a un cambio de estrategia adaptativa, hacia la ganadería, profundizando la vinculación del territorio con el sector oriental de la cordillera de los Andes, a través de los pasos cordilleranos, hacia las pampas.

Pedro de Angelis (1837) describe durante el siglo XVIII "un lugar de indios Ilamado CaIle-Calle" (De Angelis, 1837: 33), mostrando de alguna manera la permanencia de cierta frontera en el centro de la cuenca, que también se debe haber manifestado como límite entre diferenciales formas de aprovechamiento de recursos: "...saliendo de Valdivia hay como veinte leguas de montaña, y termina esta en Guinchilca en la que hay tres ríos de los dichos. El camino de la dicha montaña es ancho y llano, con algunos malos pasos, fáciles de componer. Lo más fragoso de el se puede andar por el río, hasta un lugar de indios Ilamado, Calle-Calle" (De Angelis, 1837: 33).

Las rutas muestran un territorio vinculado con el europeo hacia el oeste, con más fuerza que en el primer período. Los flujos comerciales y las relaciones entre enclaves se van consolidando en la región costera y los Ilanos centrales, mientras que la región oriental, como se dijo, prosiguió de alguna manera, bajo el dominio indígena priorizando el uso de rutas fluviales, lacustres y valles andinos.

De esta forma los enclaves españoles, se pueden observar distribuidos en el sector oeste de la cuenca, principalmente en la zona costera, en la desembocadura del río CallecaIle, donde la presencia de fuertes manifiesta un claro control español. Cabe destacar que, asociado a estos enclaves se encuentran tierras despejadas para cultivos y áreas deforestadas, producto de la recuperación española del territorio y del progresivo avance sobre 
el bosque a partir de una lógica mercantilista que integraba distintos territorios de la corona española.

La presencia de astilleros en torno a la entrada a la cuenca está vinculada al tránsito fluvial y a una actividad extractiva del bosque por parte de los peninsulares ibéricos.

Hacia el siglo XVIII se referían de esta forma a la configuración entre zonas despejadas y bosques en torno a la misión de San José de la Mariquina: "...tiene este valle seis leguas y dos de ancho (cultivos),... siendo lo restante incapaz de este beneficio por estar ocupado de montaña y bosques... (que) sirven de cobijo a muchos leones, toros y bacas brabas, que se han ido procreando con el tiempo de las que acaso se huyeron de las manadas de los antiguos españoles" (Archivo Franciscano, San- tiago, 1975). Continúa explicando el narrador, la ubicación y cantidad de población de ocho parcialidades en la misma zona, y termina afirmando: "todos los dichos indios son muy trabajadores y siembran de todas las especies de granos y menestras que hay en el país, no solo lo bastante para mantenerse sino también para vender a los españoles en bastante cantidad" (Archivo Franciscano, Santiago, 1775).

Para la construcción de la carta sobre ocupación y ambiente en el período de Independencia y colonización eurochilena (1810-1890) sintetizada en la Figura $N^{\circ} 4$, se contó con una mayor cantidad y precisión de citas, lo que está en directa relación con varios aspectos, por una parte la necesidad del gobierno chileno de establecer áreas para una colonización planificada, pero también por las exhaustivas descripciones que

Figura $\mathrm{N}^{\circ} 4$

Ambiente y uso del suelo en el período de independencia y colonización eurochilena (1810-1890)

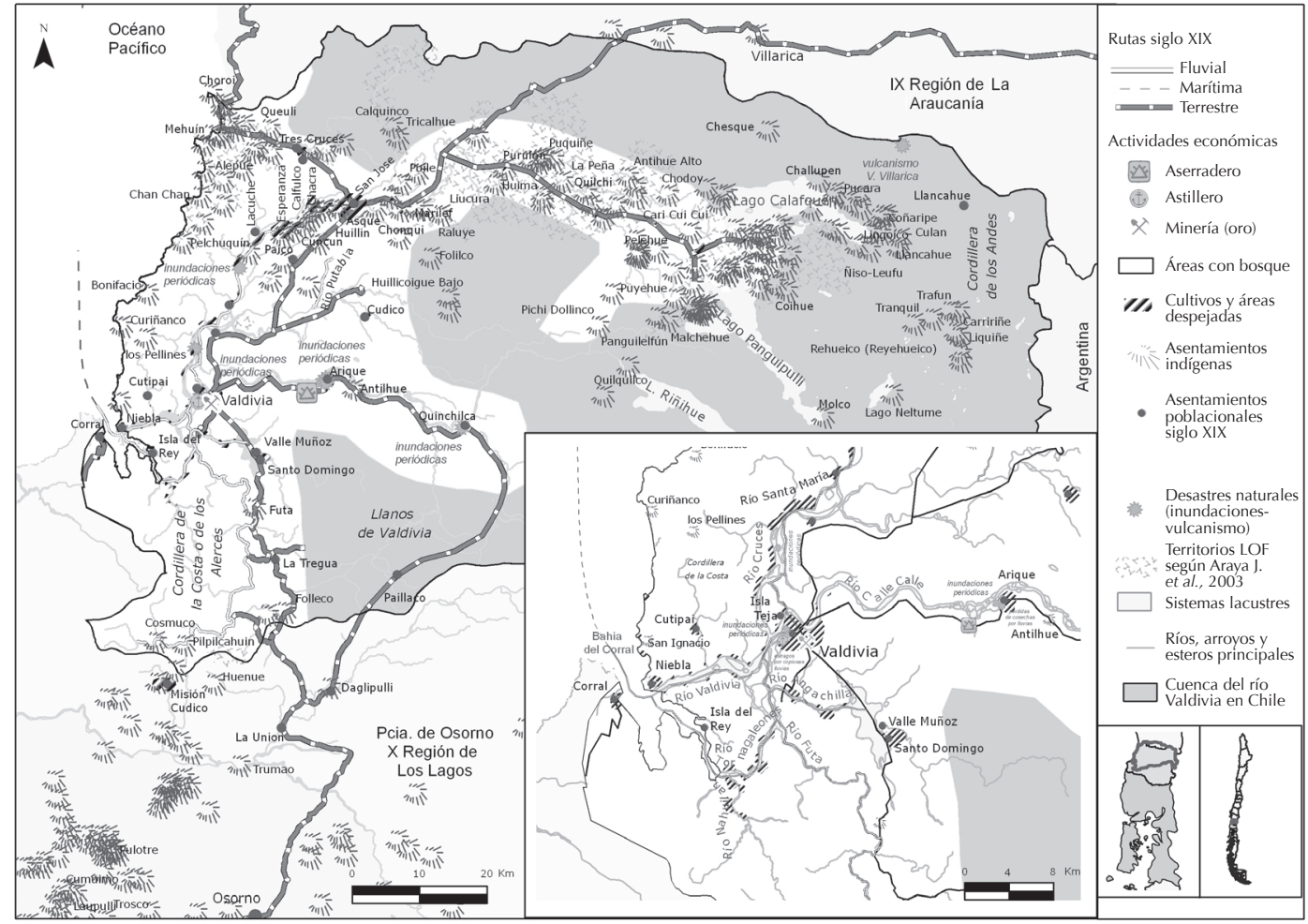

Fuente: Elaboración propia. 
se encuentran de viajeros (Treutler, 1861), naturalistas (Darwin, Philippi), funcionarios encargados de la colonización y de las tierras (principalmente documentos de Ministerios del Interior), el reconocimiento del territorio, ríos y costas (Domeyko, 1850; Vidal Gormaz, 1870), entre otros. Aun así existieron amplias áreas con densos bosques, dentro de la cuenca, que por su difícil acceso y su desconocimiento no figuran en las fuentes consultadas, especialmente en los sectores andinos. Esta situación se refleja en la referencia "área con bosques según fuentes" por lo tanto, no significa necesariamente que no exista bosque en el resto de la cuenca, sino posiblemente solo desconocimiento. De esta forma se establecen niveles de certeza de la información, que en los períodos anteriores no fue posible.

Para este último período estudiado se extrajeron 158 citas históricas. Una particularidad es que más del $60 \%$ fueron aprovechadas para los procesos ambientales propiamente dichos. Otras fuentes bibliográficas interesantes utilizadas son: Sanfuentes y Amunátegui, Feliú Cruz, Blancpain (1985) y Pérez Rosales (1852; 1859).

Se observa una mayor presencia de asentamientos indígenas en una franja que, en sentido este-oeste ocupa principalmente la parte norte de la cuenca, desde la costa, abarcando el cordón Mahuidanche-Lastarria, hasta el límite andino en que se encuentra un poblamiento importante en torno a los lagos cordilleranos. Así lo demuestran las descripciones realizadas por viajeros, como Paul Treutler (1958), al relatar un viaje desde San José de la Mariquina hacia el noreste, con dirección a la cordillera andina. Después de una hora de avanzar por terrenos boscosos y por pastizales, pasa por los caseríos indígenas de Chonqui y Quechupulli, para Ilegar, luego, al de Marilef. Luego de cabalgar entre cerros cubiertos de espesos bosques vírgenes, Ilega a un altiplano donde encuentra una choza, grandes manzanos y campos cultivados. Desde allí realiza un largo recorrido remontando el río Cruces y el Leufucahue, donde encuentra varios caseríos indígenas y algunos trechos de selva. Finalmente, Treutler arriba al lago Trailafquén, denominado ahora, Calafquén.

La distribución antes mencionada, también se observa en los territorios lof, más contem- poráneos (Araya et al., 2003), que justifica y muestra un arrinconamiento de las comunidades hacia las tierras altas, menos productivas y más boscosas, presentes hasta la actualidad en esta franja septentrional de la cuenca.

Darwin (1951) marcaba el límite entre selva y llanos y la importancia de la agricultura indígena: "Cudico es un distrito intermedio entre la selva y los Ilanos. Se ve un gran número de cottages con campos de trigo y de patatas que pertenecen casi todos a indios" (Darwin, 1951: 357).

A su vez, Vidal Gormaz (1870), en el reconocimiento del río Valdivia, describe las riberas boscosas, cubiertas de exuberante vegetación de sus afluentes (Angachilla, Cantera, Tornagaleones, Naguilan, Cutipai), notándose, no obstante, de trecho en trecho "algunas chozas, cuyos habitantes cultivan pequeños retazos de tierra i labran madera de varias clases" (Vidal Gormaz, 1870: 274).

Probablemente buena parte de la exuberante vegetación encontrada por los viajeros y exploradores del siglo XIX, debió haber tenido poco más de dos siglos de existencia en importantes áreas. Pues la reforestación del periodo de recuperación indígena, no tuvo un corte abrupto en la tercera etapa de repoblamiento español. Esta vuelta al poder español, no habría significado un avance importante y rápido sobre los bosques alejados de los principales núcleos poblados en torno a Valdivia, San José de la Mariquina y Arique. Incluso pudo haberse producido un incremento de la superficie forestal en ciertas áreas del este de la cuenca donde los colonizadores no ejercían una fuerte presión sobre los grupos indígenas que mantenían relativa autonomía en sus formas de ocupación territorial, constituyéndose los lagos cordilleranos y el acceso a las zonas altas, dominio de las Araucarias, en un relicto cultural indígena.

Vidal Gormaz (1870) destaca la recuperación de los bosques debido a la menor presión demográfica indígena: "al recorrer nosotros el territorio litoral i parte del interior, comprendido entre el río Imperial y el archipiélago de Chiloé por el espacio de cuatro años consecutivos, hemos podido notar el incremento rápido de los bosques. Por todas partes, se notan vestigios de rucas e inmensos 
retoñales al paso que los desmontes modernos o más propiamente contemporáneos, son mucho más reducidos i limitados, fenómeno que hacer ver la disminución de la población indígena i con ello el incremento de los bosques" (Vidal Gormaz, 1870: 275).

La lógica de habitar de los colonos eurochilenos se manifiesta afianzada en la depresión intermedia y valles costeros en sentido norte-sur a través de rutas, asentamientos humanos y explotación de los recursos. Sin embargo, se observan algunas vías de comunicación que avanzan hacia el este, lo que refleja una necesaria vinculación con el territorio indígena, con su evangelización, educación formal y preferentemente, con la explotación de sus bosques. Numerosas citas hablan de la necesidad de reparar puentes y caminos destruidos para recuperar la comunicación con otros territorios: "...caminos de Cuyincagüe a San José y de esta villa a Purulon... El camino en cuestión es uno de los principales de la provincia, tanto por la gran población, fundos e industrias a que sirve, como también por ser la arteria que comunica la ciudad de Valdivia, como centro de comercio, con los florecientes pueblos de Villa Rica, Pucón, Palquin y aún los fronterizos con Chile de la República Argentina, que se sirven del paso de Villa Rica, como que es uno de los mejores de la Cordillera de los Andes" (ANCH, 1759: 18).

A su vez las rutas, externas a la cuenca, muestran cierta relación con los sectores surorientales, pero principalmente con los asentamientos situados al sur de Valdivia, tratando de recuperar los itinerarios españoles hacia los Ilamados Llanos de Osorno.

Cabe destacar que más allá de este patrón de orientación de las vías de comunicación, la mayor conectividad se manifiesta en algunas rutas principales terrestres y marítimas que figuran con mayor mención en las fuentes, como son las que comunican Valdivia con Osorno, San José de la Mariquina y Santiago. Esto refleja la posición de Valdivia como núcleo económico y comercial de la región (Figura $\mathrm{N}^{\circ} 5$ ).

A partir del período de la Independencia los enclaves europeos de períodos anteriores se constituyen en asentamientos de colonos chilenos y aparecen en mayor cantidad, acompañando el avance hacia las regiones orientales. Por otra parte, es importante destacar que algunos territorios de parcialidades indígenas, que fueron ocupadas por el español, siguieron un proceso de consolidación que se profundiza en el período eurochileno, como es el caso de Arique, Quinchilca y San José de la Mariquina.

También en este último período se observa una mayor presencia de actividades económicas (astilleros, aserraderos y extracción de oro) localizadas sobre los ríos Valdivia y Callecalle, principales vías fluviales de la cuenca. La explotación maderera seguía siendo un recurso muy valorado y explotado principalmente en el occidente de la cuenca como destaca Treutler (1958): "gracias a las inmensas selvas que había en la provincia de Valdivia y que se encontraban inmediatas a la orilla del mar o junto a los ríos navegables, uno de los principales artículos de exportación eran las maderas, las cuales tenían excelente calidad, lo que favorecía su comercio" (Treutler, 1958: 291). En el mismo sentido, Sanfuentes y Amunátegui (1925), cuantifican la extracción de madera para mediados del siglo XIX: "se calculan haberse cortado en 1845 seis mil vigas, cinco mil quinientas viguetas, diez mil tijerales, cuarenta mil cuartones, sesenta umbrales, dos mil postes, cuatro mil tablones, treinta mil tablas, cien horcones, doscientos pilares" (Sanfuentes y Amunátegui, 1925: 96).

Es sugerente la referencia mayor a desastres naturales como inundaciones y volcanismo, situación que puede vincularse con un territorio mayormente ocupado, percibido y estudiado de acuerdo al contexto de exploración propio del siglo XIX.

Como se dijo, existe mucha más información de este período referida a la localización de bosques y cultivos. Treutler (1958), al navegar aguas arriba el río Cruces, describe la orilla occidental del cauce densamente cubierta de bosques (en las estribaciones montañosas) intercaladas con "habitaciones y tierras bien cultivadas, que se extienden hasta cerca de San José" (Treutler, 1958: 301) mientras la orilla oriental, mucho más Ilana, "se hallaba cubierta por selva virgen impenetrable, en la que solo se habían descampado algunos paños de terreno para cultivarlos" (Treultler, 1958: 301). 
Figura $\mathrm{N}^{\circ} 5$

Importancia de rutas según frecuencias en citas del período 1810-1890

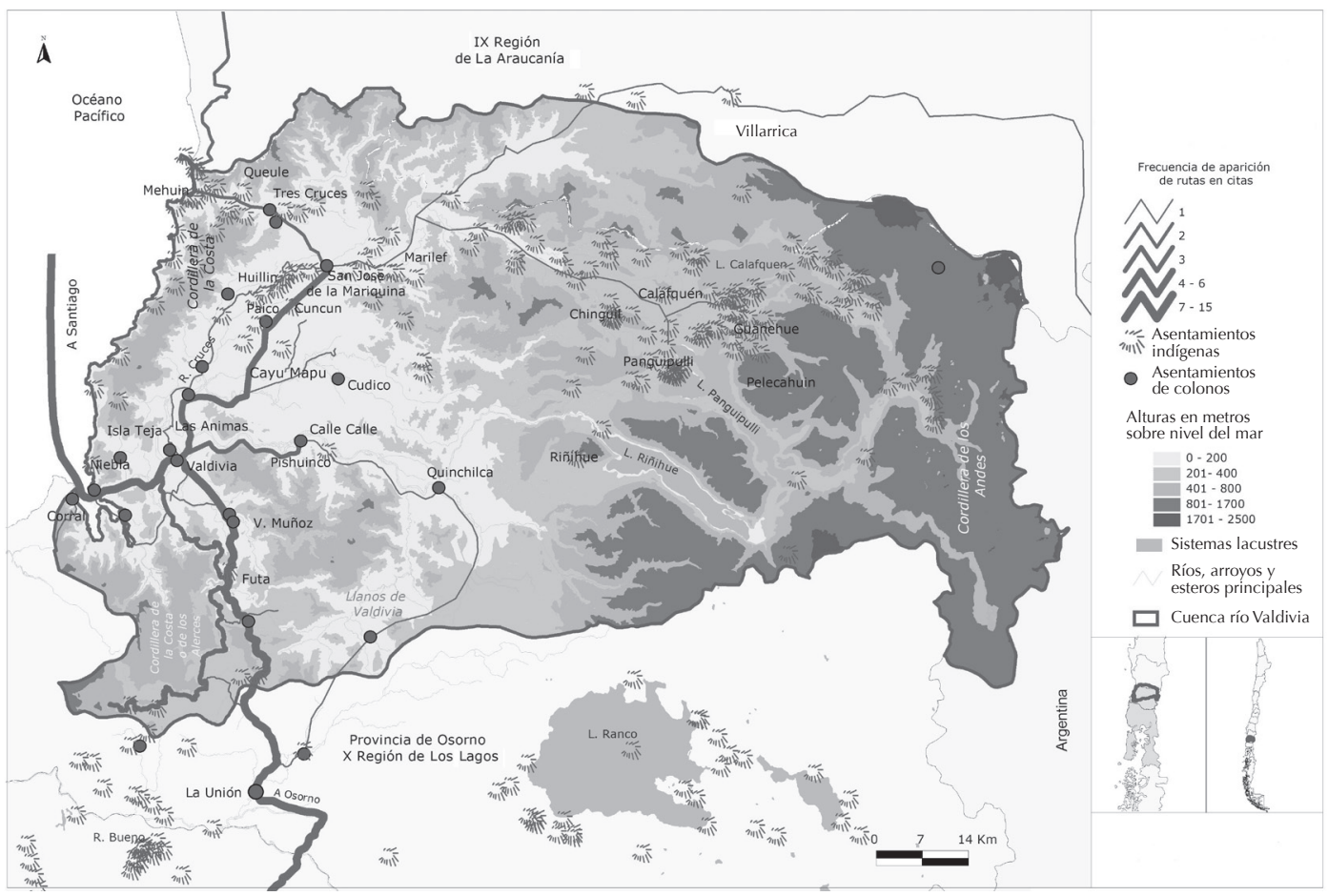

Fuente: Elaboración propia.

\section{Consideraciones finales}

Se verificó que el exuberante estado de los bosques valdivianos a mediados de siglo XIX, respondía, en muchos casos, a áreas recuperadas por la vegetación natural alrededor de dos siglos antes, una vez disminuida la población indígena y ante la incapacidad o desinterés español de avanzar hacia el este del territorio valdiviano. La gran intensidad de explotación y el rápido avance sobre la cuenca de los europeos durante el siglo XVI, no tuvo continuidad a partir de la segunda mitad del siglo XVII, con la nueva forma de apropiación territorial española. La economía colonial no volvió a mostrar el dinamismo pasado y las estrategias de dominio recurrieron a convivir con amplios territorios mapuche-huilliches. Esta situación se apoyó en negociaciones, alianzas, aculturación y comercio, y se manifestó en el espacio como dos territorios que convivían y se complementaban. El aprovechamiento del bosque en el oriente indígena era bajo, comparado con las exportaciones forestales españolas al Alto Perú del siglo XVI; y también era menor al realizado por los propios pueblos originarios en esos primeros cincuenta años de conquista ibérica donde contaban con sectores de cultivos y poblaciones bastante mayores que durante el tercer período estudiado. Como destacan Camus y Solari (2008) los indígenas, vencidos en las guerras y diezmados por enfermedades, se refugiaron en el este de la cuenca y fueron cambiando sus prácticas productivas hacia la ganadería vinculándose a la otra vertiente de la cordillera andina.

Si bien el énfasis principal de este trabajo está dado en la ocupación y aprovechamiento de tierras despejadas o existencias de superficies boscosas, se concluye también que los patrones de distribución territorial de grupos sociales y actividades interactúan con las otras variables políticas-económicas analizadas. Si bien el poder sobre ciertos territo- 
rios representa oportunidades y limitaciones, puede ser más o menos hegemónico, pero nunca es total, puesto que requiere siempre de mediaciones y negociaciones. De esta forma, la ocupación predominante de la cuenca de los grupos europeos se dio en las áreas costeras del estuario del río Valdivia y zonas de valles intermedios, con una utilización del territorio en sentido norte-sur, lo que les permitió la conectividad con el núcleo central de Santiago y Perú y les significó la posibilidad de comercio interregional e incluso con la metrópoli. Sin embargo, las posibilidades tecnológicas, económicas y políticas que había en el sector oriental de la cuenca, no dieron lugar a un predominio español, donde se tuvo que seguir negociando y aceptando un dominio territorial indígena por varios siglos.

Por otra parte, la información arqueológica demuestra que los grupos mapuche-huilliche tenían sus asentamientos -en el periodo de precontacto con el español- de manera dispersa y asociada a ambientes lacustres y ribereños en toda la cuenca (en sentido oeste a este y norte a sur). Pero progresivamente después de la conquista, se fue produciendo un arrinconamiento cada vez mayor, lo que es observable preferentemente durante el siglo XIX, en que la zona andina y las tierras altas situadas en cordones montañosos (como el cordón Mahuidanche-Lastarria), se constituyen en un relicto cultural para estos grupos.

En el segundo período estudiado se observa que el espacio en disputa de la cuenca se reorganiza en función de intereses locales. Los indígenas que expulsan y reconquistan sus espacios ancestrales, no habitan las ciudades españolas, produciéndose en esos espacios una recuperación del bosque (Valdivia, Villarrica). A su vez negocian con fuerzas holandesas que intentan dominar la cuenca pero no llegan a realizar actividades extractivas.

A partir del repoblamiento de Valdivia (a mediados del siglo XVII) y hasta inicios del siglo XIX, se produce una reorganización del espacio de la cuenca. Se producen nuevas estrategias de ocupación: diplomáticas, militares y religiosas, en que los núcleos españoles secundarios vinculan el territorio y consolidan la ocupación. Sin embargo, estas estrategias no pueden evitar la negociación y la aceptación implícita de que grandes áreas corresponden a territorio indígena, lo que expresa su hegemonía sobre cómo se habitan esos territorios y la relación que establecen con el bosque en particular.

A medida que avanza el siglo XIX, se muestra el espacio de la cuenca organizado y unificado en torno a un ideal de colonización y conectividad con los demás centros nacionales. Valdivia, como núcleo urbano principal, dinamiza, planifica y claramente explota el área circundante, estableciendo la dirección de los flujos de mercancías, transportes y habitantes. Desde mediados de siglo XIX, paulatinamente el Estado chileno tendría poder territorial sobre todos los espacios indígenas. Hacia fines de siglo, cuando el progreso eurochileno se pensaba como lineal e ilimitado, grandes superficies boscosas eran testigos de que tanto los procesos sociales como los ambientales tienen muchas marchas y contramarchas.

\section{Agradecimientos}

Agradecemos a Aldo Farías (WWF-Valdivia) por su valiosa ayuda en relación a la cartografía inicial para la construcción de las cartas históricas y a Doina Munita y Ximena Navarro por la sistematización georreferenciada de los sitios arqueológicos de la cuenca del río Valdivia (Fondecyt No 1040326).

\section{Referencias bibliográficas}

ABRAHAM, E. \& PRIETO, M. R. Contributions of historical geography to the study of process of landscape change: the case of Guanacache, Mendoza, Argentina. Bamberger Geographische Schriften, 1991, № 11, p. 309-336.

ACEITUNO, P.; PRIETO, M. R.; SOLARI, M. E.; MARTÍNEZ, A. y POVEDA, G. The 1877-1878. El Niño episode: associated impacts in South America. Climatic Change, 2009, vol. 92, No 3-4, p. 389-416.

ARAYA, J.; ANTILEF, V. y CHOCORI, B. Informe final. Valdivia: Proyecto de investigación pueblo mapuche Wijice del Chaurakawin al Pikunwijimapu, 2003.

ARCHIVO NACIONAL DE CHILE (ANCH). Fondo Intendencia de Valdivia, vol. 65 y vol. 790. Santiago: ANCH, 1759. 
ARCHIVO FRANCISCANO, SANTIAGO. EStado de la Misión de San José, año 1775. Santiago: Fondo Colegio de Chillán, volumen 3, 1975.

ARMESTO, J.; LEÓN-LOBOS, P. y KALIN, M. Los bosques templados del sur de Chile y Argentina: una isla biogeográfica. En: ARMESTO, J.; VILLAGRÁN, C. y KALIN, M. Ecología de los Bosques Nativos de Chile. Santiago: Editorial Universitaria, 1996, p. 23-28.

ARROYO, M. T. K.; ARMESTO, J. J.; ROZZI, R. y PEÑALOZA, A. Bases de las sustentabilidad ecológica y sus implicaciones para el manejo y conservación del bosque nativo en Chile. En: DONOSO, C. y LARA, A. Silvicultura de los bosques nativos de Chile. Santiago: Ed. Universitaria, 1998. p. 35-68.

BENGOA, J. Historia de los antiguos mapuches del sur. Desde antes de la llegada de los españoles hasta las paces de Quilín. Santiago: Ed. Catalonia, 2003.

BLANCPAIN, J. P. Los alemanes en Chile (1816-1945). Santiago: Ediciones Pedagógicas Chilenas y Editorial Universitaria, 1985.

CAMUS, P. y SOLARI, M. E. La invención de la selva austral. Bosques y tierras despejadas en la cuenca del río Valdivia (siglos XVI-XIX). Revista de Geografía Norte Grande, 2008, No 40, p. 5-22.

CARVALLO GOYENECHE, V. Descripción histórico-geográfica del reino de Chile. Santiago: Imprenta del Ferrocarril, Colección de Historiadores de Chile, 1861.

CASTRI, F. y DI HAJEK, E. Bioclimatología de Chile. Santiago: Editorial Universidad Católica, 1976.

DARWIN, C. Viaje de un naturalista alrededor del mundo. Buenos Aires: Librería El Ateneo, 1951.

DE AGUIRRE, J. Población de Valdivia motivos y medios para aquella fundación. Defensas del Reino del Perú, para resistir las invasiones enemigas en mar, y tierra. Alicante: Biblioteca virtual Miguel de Cervantes, 2000.

DE ANGELIS, P. Colección de obras y documentos relativos a la historia antigua y moderna de las provincias del Río de la Plata. Tomo I. Argentina: Imprenta del Estado, 1837.

DE OCAÑA, D. A través de la América del Sur. Madrid: Edición de Arturo Álvarez, Historia 16, 1987.

DE OVALLE, A. Histórica relación del Reyno de Chile. Santiago: Imprenta Ercilla, Colección de Historiadores de Chile, 1888.

DOMEYKO, I. 1802-1889. Memoria sobre la colonización en Chile. Santiago: Imprenta Julio Berlín, 1850.

DONOSO, C. Modificaciones del paisaje chileno a lo largo de la Historia. En: Valdivia, Simposium Desarrollo y Perspectivas de las disciplinas Forestales de la Universidad Austral de Chile, 1983.

DONOSO, C. Árboles nativos de Chile. Guía de reconocimiento. Valdivia: Marisa Cuneo Ediciones, 2005.

EDUCARCHILE. X Región de Los Lagos. Santiago: Educarchile, 2010. Disponible en Internet: http://www.educarchile.cl/Portal. Base/Web/verContenido.aspx?ID=130238

FARÍAS, A. Caracterización Etno-ambiental de la cuenca río Valdivia, mediante Sistemas de Información Geográfica (SIG). Santiago: Informe Fondecyt No 1040326, 2006.

FELIÚ CRUZ, G. Relación del viaje de Hendrick Brouwer a Valdivia en 1643. En: FELIÚ CRUZ, F. (ed.). Opúsculos Varios de José Toribio Medina. Santiago: Fondo Histórico y Bibliográfico José Toribio Medina, 1926, p. 78-127.

GÓNGORA MARMOLEJO, A. de. Historia de Chile desde su descubrimiento hasta el año 1575. Santiago: Imprenta Ferrocarril, Colección de Historiadores de Chile, 1862.

GONZÁlEZ DE AGÜERO, P. Descripción historial de la provincia y archipiélago de Chiloé en el reino de Chile y Obispado de Concepción dedicada a nuestro católico monarca don Carlos IV. Madrid: Imprenta de don Benito Cano, MDCCXCl, 1791.

GUARDA G. Nueva historia de Valdivia. Santiago de Chile: Ediciones Universidad Católica, 2001. 
IAN, N. G. \& ELL, P. S. Historical GIS technologies, methodologies and scholarship. New York: Cambridge University Press, 2007.

JORI, G. Recursos en Internet sobre la Historia Ambiental de Estados Unidos y Canadá. Revista Electrónica Ar@cne, 2009, No 126. Disponible en Internet: http://www. ub.edu/geocrit/aracne/aracne-126.htm

LUEBERT, F. y PLISCOFF, P. Sobre los límites del bosque valdiviano. Chloris Chilensis, 2005, $\mathrm{N}^{\circ} 1$. Disponible en Internet: http://www.chlorischile.cl/luebertvald/ luebertvald.htm

MARIÑO DE LOVERA, P. Crónica del reino de Chile. Santiago: Imprenta El Ferrocarril, Colección de Historiadores de Chile, 1861.

PÉREZ ROSALES, V. Memoria sobre la colonización de la provincia de Valdivia. Valparaíso: Imprenta del Diario, 1852.

PÉREZ ROSALES, V. Ensayo sobre Chile. Santiago: Imprenta del Ferrocarril, 1859.

POUNDS, N. J. G. Geografía histórica de Europa. Barcelona: Editorial Crítica, 2000.

PRIETO, M. R. Procesos ambientales en la antigua área palustre del oasis del Río Mendoza (1780-1930). Factores naturales y antropogénicos. Argentina: Proyecto Agencia Nacional de Promoción Científica y Tecnológica (FONCYT), 2000.

PRIETO, R.; HERRERA, G.; CASTRILLEJO, T. y DUSSEL, P. Variaciones climáticas recientes y disponibilidad hídrica en los andes argentinos chilenos (1885-1996). El uso de datos periodísticos para reconstrucciones del clima. Meteorológica, 2000, vol. 25, № 1 y 2, p. 27-43.

ROSALES, D. Historia general de el Reyno de Chile. Flandes Indiano. Santiago: Imprenta del Mercurio, 1877.

SANFUENTES, S. y AMUNÁTEGUI, M. L. Valdivia antes de la inmigración. En: BAUER, K. Fuentes del mundo que nos rodea. Valdivia: Imprenta Borneck, 1925.

SIEFERLE R. ¿Qué es la historia ecológica? En: GONZÁLEZ DE MOLINA, M. y MARTÍ-
NEZ ALIER, J. Naturaleza transformada. Barcelona: Ed. Icaria, 2001, p. 31-54.

SOLARI, M. E.; CUETO, C.; HERNÁNDEZ, F. y ROJAS, F. Constitución histórico-ambiental de los paisajes regionales: cartas temáticas de la cuenca del río Valdivia (SIG). En: Valdivia, $2^{\circ}$ Taller. Paisaje cultural, gestión territorial y patrimonio, 27 al 29 de octubre de 2009.

SOLARI, M. E.; GONZÁLEZ, M.; PAILLACHEO, F. y MARTICORENA, F. Fuego, ganado y madereo. Prácticas culturales en los bosques de Araucaria y Alerce $\left(38^{\circ}-41^{\circ} \mathrm{S}\right)$. En: Valdivia, Actas VI Congreso Chileno de Antropología 2007, en prensa.

SOLARI, M. E.; NAVARRO, X.; ADÁN, L. y GODOY M. Informe final de proyecto FONDECYT 1040326. Santiago: CONICYT, 2007.

SUBIABRE, A. y ROJAS, C. Geografía Física de la Región de los Lagos. Valdivia: Ediciones Universidad Austral de Chile, 1994.

TREUTLER, P. Andanzas de un alemán en Chile, 1851-1863. Santiago: Editorial del Pacífico, 1958.

TREUTLER, P. La provincia de Valdivia i los Araucanos. Santiago: Imprenta Chilena, 1861.

USAURO MARTÍNEZ, P. La verdad en Campaña. Relación histórica de la plaza, puerto y presidio de Valdivia. 1782. En: ANRIQUE, N. Biblioteca Jeográfico-Hidrográfica de Chile. Santiago: Imprenta Elzeviriana, 1898, p. 39-218.

VIDAL GORMAZ, F. Reconocimiento del río Valdivia $i$ de las costa comprendida entre el Corral y Reloncaví. Santiago: Memoria del Ministerio de Guerra y Marina, 1870.

VIVAR, G. Crónica y relación copiosa y verdadera de los reinos de Chile. Berlín: Biblioteca Latinoamericana Ed. Colloqium Verlang, 1979.

WHEATLEY, D. \& GILLINGS, M. Spatial Technology and Archaeology. London: Taylor \& Francis, 2002.

WORSTER, D. The end of the earth, perspectives on moderm evironmental history. Cambridge: Cambridge University Press, 1989. 